\title{
Insulin entry into muscle involves a saturable process in the vascular endothelium
}

\author{
S. Majumdar • A. J. Genders • A. C. Inyard • V. Frison • \\ E. J. Barrett
}

Received: 28 July 2011 / Accepted: 22 September 2011 /Published online: 15 October 2011

(C) Springer-Verlag 2011

\begin{abstract}
Aims/hypothesis Insulin's rate of entry into skeletal muscle appears to be the rate-limiting step for muscle insulin action and is slowed by insulin resistance. Despite its obvious importance, uncertainty remains as to whether the transport of insulin from plasma to muscle interstitium is a passive diffusional process or a saturable transport process regulated by the insulin receptor.

Methods To address this, here we directly measured the rate of ${ }^{125}$ I-labelled insulin uptake by rat hindlimb muscle and examined how that is affected by adding unlabelled insulin at high concentrations. We used mono-iodinated $\left[{ }^{125} \mathrm{I}\right]$ $\mathrm{Tyr}^{\mathrm{A} 14}$-labelled insulin and short $(5 \mathrm{~min})$ exposure times, combined with trichloroacetic acid precipitation, to trace intact bioactive insulin.

Results Compared with saline, high concentrations of unlabelled insulin delivered either continuously (insulin clamp) or as a single bolus, significantly raised plasma ${ }^{125} \mathrm{I}$ labelled insulin, slowed the movement of ${ }^{125}$ I-labelled insulin from plasma into liver, spleen and heart $(p<0.05$, for each) but increased kidney ${ }^{125}$ I-labelled insulin uptake. High concentrations of unlabelled insulin delivered either continuously (insulin clamp), or as a single bolus, significantly decreased skeletal muscle ${ }^{125}$ I-labelled insulin clearance $(p<0.01$ for each). Increasing muscle perfusion by electrical stimulation did not prevent the inhibitory effect of unlabelled insulin on muscle ${ }^{125} \mathrm{I}$ labelled insulin clearance.
\end{abstract}

S. Majumdar and A.J. Genders contributed equally to this study.

S. Majumdar · A. J. Genders · A. C. Inyard · V. Frison •

E. J. Barrett $(\bowtie)$

University of Virginia Health System,

PO Box 801410, 450 Ray C. Hunt Drive,

Charlottesville, VA 22908, USA

e-mail: ejb8x@virginia.edu
Conclusions/interpretation These results indicate that insulin's trans-endothelial movement within muscle is a saturable process, which is likely to involve the insulin receptor. Current findings, together with other recent reports, suggest that trans-endothelial insulin transport may be an important site at which muscle insulin action is modulated in clinical and pathological settings.

Keywords Insulin · Insulin transport · Muscle · Trans-endothelial transport

\section{Abbreviation \\ TCA Trichloroacetic acid}

\section{Introduction}

Multiple studies have demonstrated that insulin's transfer from plasma to muscle interstitium is the rate-limiting step for muscle insulin action [1-7]. However, controversy persists as to whether within muscle insulin leaves the vasculature by a passive process [8] or by a saturable process that may involve an insulin receptor-dependent, endothelial cell-mediated pathway [9]. Measurement of plasma insulin disappearance has consistently shown that whole body insulin clearance involves a saturable process $[10,11]$. However, the kinetic properties of insulin transfer from plasma into muscle interstitium could not be assessed from measurements of whole body insulin clearance, as the liver and kidneys are the major organ sites responsible for this clearance.

Although kinetic modelling of intravenously injected native insulin has strongly indicated that uptake of insulin by muscle determines the glucose disposal rate during an insulin clamp, it has not identified whether this process is 
saturable [12]. To our knowledge, data quantifying muscle radioiodinated insulin clearance is limited to a study by Sonksen et al. [10] who reported that canine hindlimb uptake of ${ }^{131}$ I-labelled insulin (measured by arterial-venous difference) was inhibited by high concentrations of unlabelled insulin, which is consistent with a saturable process. However, using the clamp method and lymphatic sampling to assess muscle interstitial insulin concentrations over time, Steil et al. [8] did not observe saturable insulin uptake when comparing a high physiological to a pharmacological insulin infusion. In contrast, we examined skeletal muscle insulin clearance in the human forearm using arterial-venous insulin concentration differences and brachial artery flow. These measurements were made at steady state and indicated that muscle insulin clearance declined when insulin concentrations were raised from fasting to mid-physiological hyperinsulinaemic concentrations [13]. This suggests that insulin uptake is a saturable process. However, these steady-state analyses could not differentiate whether this saturation occurred at the level of the endothelial cell, the muscle cell or both.

We have recently shown that insulin moves across the endothelium via a trans-cellular pathway in rat muscle [9]. We also found that, in cultured bovine endothelial cells, insulin uptake was blocked by unlabelled insulin, by IGF-1 and by antibody to the IGF-1 receptor, consistent with transport mediated by either the insulin or IGF-1 receptor [9]. However, the behaviour of cultured endothelial cells may differ significantly depending on the tissue source from which the cells derive, the time in culture, the culture conditions and other factors. As a result, the significance of such findings from cultured cell systems for in vivo muscle insulin uptake is uncertain.

In the current study, we directly examined whether ${ }^{125} \mathrm{I}-$ labelled insulin uptake by rat hindlimb muscle was affected by the presence of unlabelled insulin administered either prior to or concomitant with labelled insulin injection. We used very short exposure times to the ${ }^{125}$ I-labelled insulin (5 min) to minimise the contribution to clearance of: (1) ${ }^{125}$ I-labelled insulin degradation products to the tracer derived estimates of insulin clearance; and (2) cells other than endothelial cells.

\section{Methods}

Male Sprague-Dawley rats weighing approximately $250 \mathrm{~g}$ were fed ad lib until the evening prior to the study, when food was withdrawn. The animals were studied $16 \mathrm{~h}$ later. The study protocol was approved by the University of Virginia Animal Care and Use Committee and followed the 'Principles of laboratory animal care' (NIH publication no. 85-23, revised 1985). Animals were anaesthetised with pentobarbital $(50 \mathrm{mg} / \mathrm{kg}$ i.p.) and the internal jugular vein and contralateral internal carotid artery were cannulated with PE50 tubing (Becton Dickinson, Franklin Lakes, NJ, USA), as previously described [14]. A tracheotomy tube was placed to protect the airway, and pentobarbital was continuously infused via the carotid artery line to maintain stable anaesthesia throughout the experiments. For the insulin studies each animal had an electrode (suture hooks) placed in each hindlimb; one was a sham and the other (right hindlimb) was attached to an HSE Stimulator P (Hugo Sachs Elektronik-Harvard Apparatus GmbH, MarchHugstetten, Germany) for subsequent low frequency electrical stimulation (5 V at $0.1 \mathrm{~Hz}$ ). Blood pressure was monitored via the carotid artery with a pressure transducer (Harvard Apparatus, Hollison, MA, USA). Following instrumentation, we waited for $30 \mathrm{~min}$ before beginning the experimental protocols to allow haemodynamic and anaesthesia stabilisation. Rats were studied under one of the following three protocols.

Protocol 1: insulin clamp studies Ten rats received either a $2 \mathrm{~h}$ infusion of heparinised $(5 \mathrm{U} / \mathrm{ml})$ normal saline at $30 \mu \mathrm{l} / \mathrm{min}$ ( $n=5$, control study), or a $2 \mathrm{~h}$ high-dose $\left(100 \mathrm{mU} \mathrm{kg}^{-1} \mathrm{~min}^{-1}\right)$ insulin clamp ( $n=5$; see Fig. 1). Control infusions and insulin clamps were continued for $120 \mathrm{~min}$ prior to initiation of further interventions, and blood glucose was sampled every $5 \mathrm{~min}$ for the first $60 \mathrm{~min}$ of the experiment, and then every $10 \mathrm{~min}$ until completion. Glucose was measured with an Accucheck Aviva Advantage glucometer (Roche, Indianapolis, IN, USA). During the insulin clamp, euglycaemia was maintained by the infusion of a $30 \%$ dextrose solution at a variable rate. Saline infusion in controls was intended to approximately match volume of glucose+ insulin infusions in the euglycaemic clamp animals. Control and clamp studies were conducted on separate days in an alternating pattern to allow this volume approximation. At 120 min into the insulin clamp or saline infusion a blood

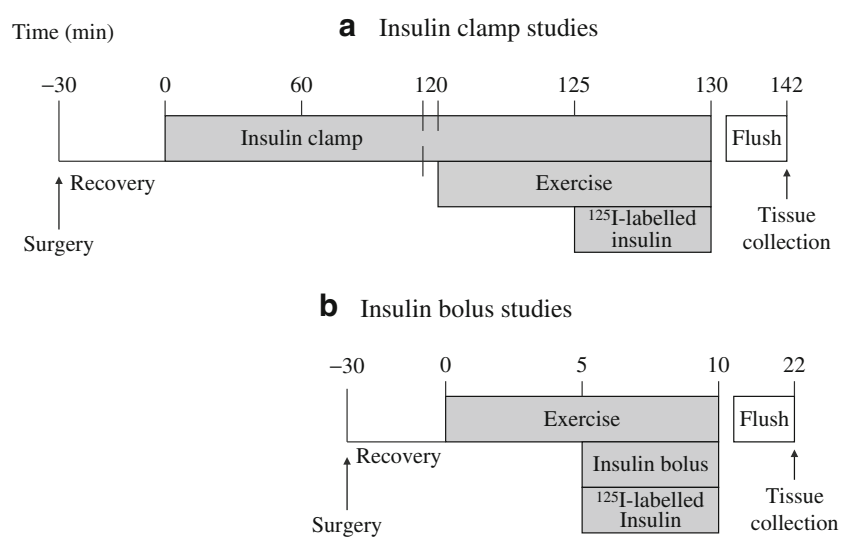

Fig. 1 Outline of protocol 1 (a) the insulin clamp and protocol 2 (b) the insulin bolus. For the control studies, saline was substituted for the insulin infusion (a) and for the insulin bolus (b) 
sample was drawn for serum insulin measurement. This was followed by a $10 \mathrm{~min}$ period of $0.1 \mathrm{~Hz}$ electrical stimulation to the right hindlimb, while the control limb received no stimulation. This level of electrical stimulation has been shown to near maximally recruit muscle microvasculature [14]. After $5 \mathrm{~min}$ of electrical stimulation, $0.55 \mathrm{MBq}$ (specific activity $81.4 \mathrm{TBq} / \mathrm{mmol}$ ) of ${ }^{125}$ I-labelled insulin $\left(\left[{ }^{125} \mathrm{I}\right] \mathrm{Tyr}^{\mathrm{A} 14}\right.$-labelled insulin, PerkinElmer, Waltham, MA, USA) was injected into the jugular vein in $250 \mu$ l of heparinised normal saline. After an additional $5 \mathrm{~min}$, a $1 \mathrm{ml}$ blood sample was taken for measurement of trichloroacetic acid (TCA)-precipitable ${ }^{125}$ I-labelled insulin. The electrical stimulation was then stopped and the rat was killed via a bolus intracardiac injection of pentobarbital. The vasculature was flushed with $120 \mathrm{ml}$ of chilled heparinised normal saline at $10 \mathrm{ml} / \mathrm{min}$ to remove the blood components within the vasculature [14].

Protocol 2: insulin bolus studies After the 30 min period of haemodynamic stabilisation, a blood sample for insulin was collected and the right hindlimb was electrically stimulated at $0.1 \mathrm{~Hz}$ for the next $10 \mathrm{~min}$. After $5 \mathrm{~min}$ the rats received an intravenous bolus injection of either $1 \mathrm{U}$ of regular human insulin diluted in $250 \mu \mathrm{l}$ of heparinised normal saline or $250 \mu \mathrm{l}$ normal saline $\left(n=5\right.$ each). ${ }^{125}$ I-labelled insulin at $0.055 \mathrm{MBq}$ (specific activity $81.4 \mathrm{TBq} / \mathrm{mmol}$ ) was included with each treatment (insulin bolus or saline control). After 5 additional min a $1 \mathrm{ml}$ blood sample was taken for measurement of TCA-precipitable ${ }^{125}$ I-labelled insulin, the animal was killed, and the vasculature flushed as noted above.

Three considerations drove our study design. The simple comparison of skeletal muscle ${ }^{125}$ I-labelled insulin uptake in the presence or absence of a high concentration of unlabelled insulin given simultaneously (protocol 2) should answer whether muscle uptake of insulin from the vascular compartment is a saturable process. However, a previous report had suggested that insulin transport into muscle (perhaps by insulin acting to enhance muscle capillary perfusion), disproportionately enhances trans-endothelial insulin transport beyond even that expected from simple increases of insulin concentration [8]. We therefore used two manoeuvres to minimise any contribution from changes in muscle perfusion that might be introduced by the large bolus dose of insulin. The first manoeuvre was to use the high-dose insulin clamp (protocol 1), which would assure that insulin-induced capillary recruitment occurred long before administering the dose of ${ }^{125}$ I-labelled insulin. The second was to stimulate one hindleg electrically at a stimulation frequency that we have previously shown essentially fully recruits hindlimb microvasculature. This latter manoeuvre was done both in the animals treated with the insulin clamp as well as those receiving a bolus of unlabelled insulin, together with ${ }^{125}$ I-labelled insulin. In aggregate, we believe that these two manoeuvres remove the potential confounding effects of vascular perfusion on insulin uptake. Finally, as the tissue harvesting required anaesthesia, we elected to study animals that were anaesthetised throughout the insulin bolus or clamp studies in order to have a steady state. The alternative of administering the isotope and unlabelled insulin to an awake animal, and then anaesthetising within the next $5 \mathrm{~min}$ to allow prompt harvesting of tissues, could result in major haemodynamic changes with the acute induction of anaesthesia.

Protocol 3: inulin studies As a control, the uptake and clearance of $\left[{ }^{3} \mathrm{H}\right]$ inulin (Perkin Elmer, Boston, MA, USA) was measured using a similar experimental protocol as for the insulin bolus studies. After a $30 \mathrm{~min}$ period of haemodynamic stabilisation, the rats received an intravenous bolus injection of either $0.55 \mathrm{MBq}\left[{ }^{3} \mathrm{H}\right]$ inulin (specific activity $14.8 \mathrm{GBq} / \mathrm{g}$ ) in $250 \mu \mathrm{l}$ heparinised saline or $0.55 \mathrm{MBq}\left[{ }^{3} \mathrm{H}\right]$ inulin with $45 \mu \mathrm{g}$ unlabelled inulin diluted in $250 \mu \mathrm{l}$ heparinised saline. After $5 \mathrm{~min}$, a $1 \mathrm{ml}$ blood sample was taken for measurement of $\left[{ }^{3} \mathrm{H}\right]$ inulin, the animal was killed and the vasculature flushed as before. The hindlimb skeletal muscle, liver and kidney were then collected, frozen immediately in liquid nitrogen and stored at $-80^{\circ} \mathrm{C}$. Tissues were weighed, powdered, homogenised in water and spun. The radioactivity in the supernatant fraction was counted using a liquid scintillation counter (LS6500, Beckman Coulter, Brea, CA, USA).

Tissue harvesting and analysis After flushing with cold saline, skeletal muscle samples were taken from both hindlimbs, frozen immediately in liquid nitrogen, and stored at $-80^{\circ} \mathrm{C}$. They were subsequently weighed, powdered, mixed with $30 \%$ TCA, spun down and the supernatant fraction removed. The radioactivity in the total muscle extract and in the TCA pellets was counted using a gamma counter (LKB-Wallac CliniGamma 1272, Wallac Oy, Turku, Finland). Other organs were also harvested in selected experiments in the following order: liver, kidneys, heart, spleen, epididymal fat pad and urine (via bladder puncture). Tissues were weighed and both total and TCAprecipitable radioactivity were measured. All tissues tested, except blood and urine, were allowed to dry in an oven for $24 \mathrm{~h}$ after wet weight was obtained on four separate occasions. The dry weight was obtained and the ratio of dry to wet weight was calculated for individual tissue types.

Statistical analysis The results are expressed as mean \pm standard deviation. Statistical analysis was performed using Sigmastat software. Two sided Student's $t$ testing was performed using equal variances. Significance was set at $p<0.05$. 


\section{Results}

Following intravenous injection, ${ }^{125}$ I-labelled insulin is rapidly cleared from the circulation, which results in the appearance in the circulation of iodinated degradation peptides and free iodide [11]. The percentage of ${ }^{125} \mathrm{I}-$ labelled insulin as a function of the total ${ }^{125}$ I-iodine content in the blood at 5 min after injection is shown in Fig. 2. This was most apparent in the animal groups that received saline (Fig. 2 clamp control and bolus control), in which after 5 min only approximately $80 \%$ of the radioactivity in the blood was present as material that was precipitated by TCA. In animals that received a large dose of unlabelled insulin (insulin clamp and insulin bolus studies), a significantly greater fraction of the label $(90-95 \%)$ was still present in the blood in its intact form after $5 \mathrm{~min}$. Within skeletal muscle the fraction of radioactive label that was precipitated by TCA was less than that in blood ( $p<$ 0.05 , for each group). This indicates either that there is some degradation of insulin within the muscle tissue or that ${ }^{125}$ I-iodine that is either free or associated with small peptides in plasma can enter muscle more rapidly than intact ${ }^{125}$ I-labelled insulin.

As shown in Fig. 3, following simultaneous injection of ${ }^{125}$ I-labelled insulin with a bolus of unlabelled insulin, the liver, kidney, heart and spleen extracted insulin from the circulating plasma. Adipose tissue took up very little of the injected insulin. The large uptake by the kidney probably indicates a large filtered load of ${ }^{125} \mathrm{I}$-labelled insulin that is in the process of being reabsorbed and again added to the circulation. Clearly ${ }^{125}$ I-labelled insulin uptake by the liver,

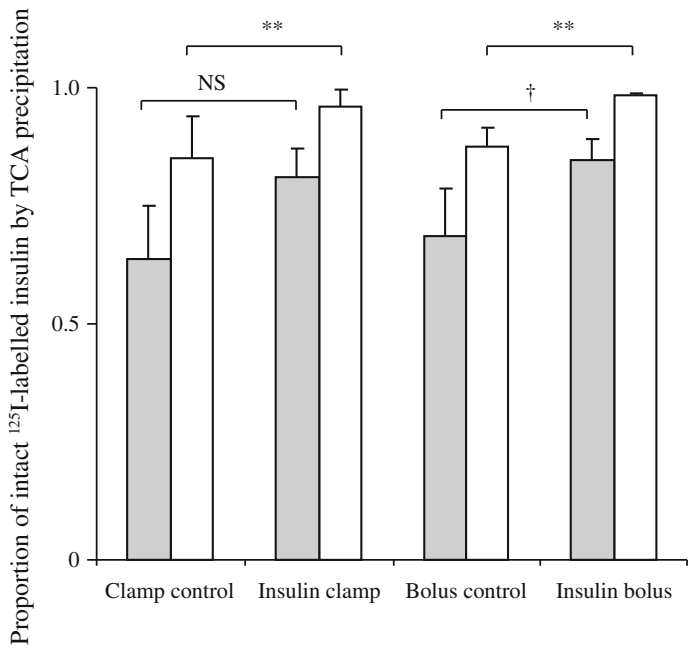

Fig. 2 The fraction of total ${ }^{125} \mathrm{I}$ present as intact ${ }^{125} \mathrm{I}$-labelled insulin in blood (white bars) and muscle (grey bars) $5 \mathrm{~min}$ after tracer injection in the insulin-treated (insulin clamp and bolus) groups vs controls. A greater fraction of ${ }^{125} \mathrm{I}$ present in the muscle was not TCAprecipitable relative to the blood $(p<0.05$, for each of the four experimental groups). ${ }^{* *} p<0.01 ;{ }^{\dagger} p<0.02$. Error bars represent SD

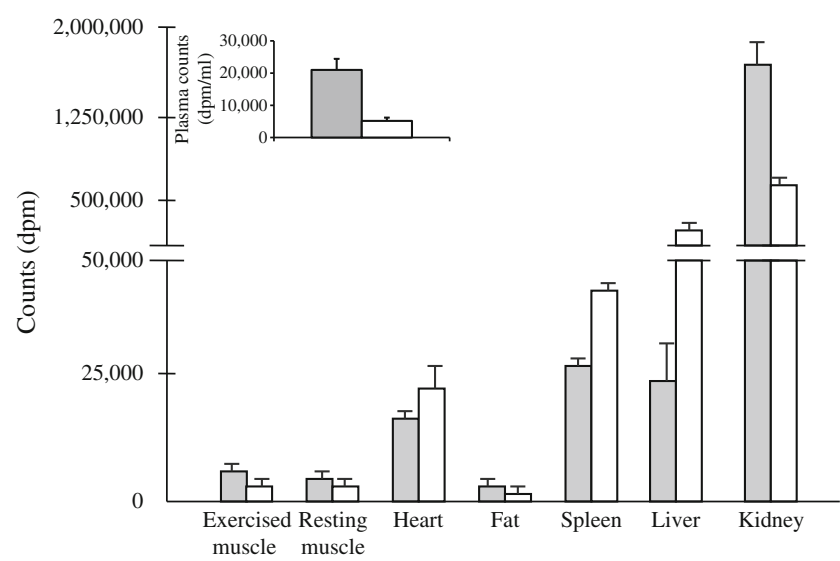

Fig. $3{ }^{125}$ I-labelled insulin in various tissues at $5 \mathrm{~min}$ after tracer injection accompanied by either an insulin bolus (grey bars) or saline (white bars) ( $n=3$ each). Note plasma counts are higher when unlabelled insulin is given (inset). The uptake of ${ }^{125}$ I-labelled insulin in the kidney is greatly increased relative to other tissues particularly when insulin treatment is given, and there is a relative decrease in insulin uptake in the liver, spleen and heart, with insulin bolus treatment. Amounts are in counts (dpm) per g dry tissue. In the kidney $>95 \%$ of the ${ }^{125}$ I-labelled insulin was intact in both insulin and saline treated animals. Error bars represent SD

spleen and heart is diminished when there is a large pool of unlabelled insulin, consistent with uptake being a saturable process. This occurred despite the approx. fourfold higher plasma ${ }^{125}$ I-labelled insulin concentration in the animals receiving the bolus of unlabelled insulin (Fig. 3). This was not seen in the kidney.

In order to take into consideration the differences in plasma radioactivity between the rats that received only ${ }^{125} \mathrm{I}$ labelled insulin and saline compared with those that received ${ }^{125}$ I-labelled insulin with high concentrations of unlabelled insulin, we measured the clearance of radiolabelled insulin by skeletal muscle $\left({ }^{125}\right.$ I-labelled insulin clearance $={ }^{125}$ I-labelled insulin uptake [dpm per gram dry weight over $5 \mathrm{~min}] /$ plasma ${ }^{125}$ I-labelled insulin $[\mathrm{dpm} / \mathrm{ml}]$ ). Figure $4 \mathrm{a}$ illustrates the clearance of ${ }^{125}$ I-labelled insulin by electrically stimulated and resting hindlimb skeletal muscle in animals studied using the insulin clamp or receiving only saline. In both the electrically stimulated and resting muscle the clearance of ${ }^{125}$ I-labelled insulin was diminished relative to the saline control. As there were no differences between the exercise and the resting muscle these data were pooled in Fig. 4b.

The clearance of ${ }^{125}$ I-labelled insulin given along with a bolus of unlabelled insulin or saline is shown in Fig. 5. In this study, clearance was significantly inhibited by the accompanying bolus of unlabelled insulin in both the resting and the electrically stimulated hindlimb muscle. In addition, in the animals receiving the insulin bolus, uptake was greater in the electrically stimulated compared with the resting hindlimb. It is likely that this was not seen during the insulin clamp as the insulin per se would have recruited microvas- 
a
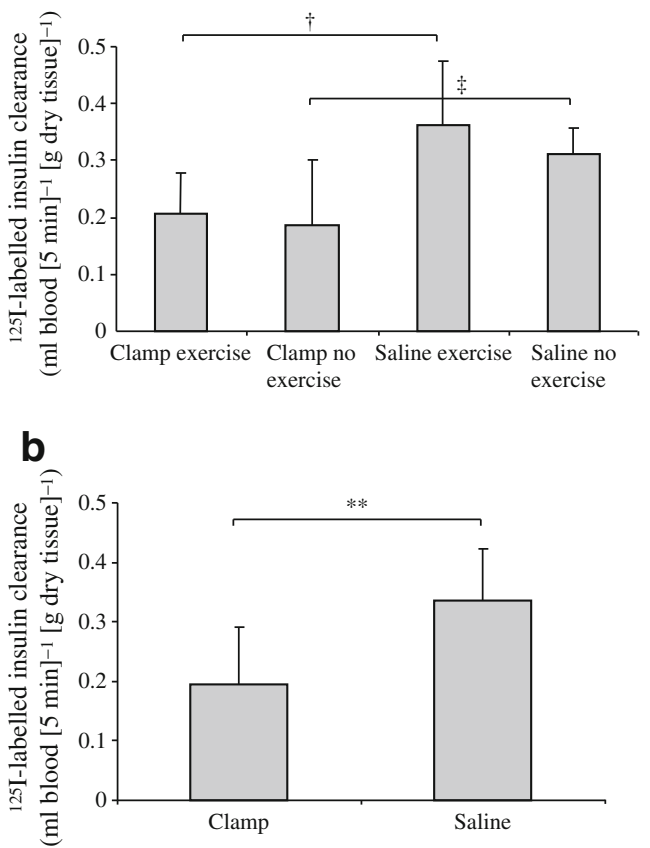

Fig. 4 a Insulin clearance in insulin clamp vs control animals separated by limbs exposed to exercise vs those that were not exercised. Differences between insulin clamp and controls were significant, but differences between exercised and non-exercised limbs were not. b Comparison of insulin clearance between insulin clamp and control animals using all limbs combined (exercised and nonexercised). There was a significant reduction in insulin clearance in the insulin clamp treated animals. ${ }^{* *} p<0.01,{ }^{\dagger} p=0.035,{ }^{\star} p=0.055$. Error bars represent SD

culature prior to even initiating muscle contraction. There was a tendency for electrical stimulation to increase ${ }^{125} \mathrm{I}$ labelled insulin clearance by the hindlimb in animals receiving only saline and radiolabelled insulin, although this did not reach statistical significance $(p=0.077)$

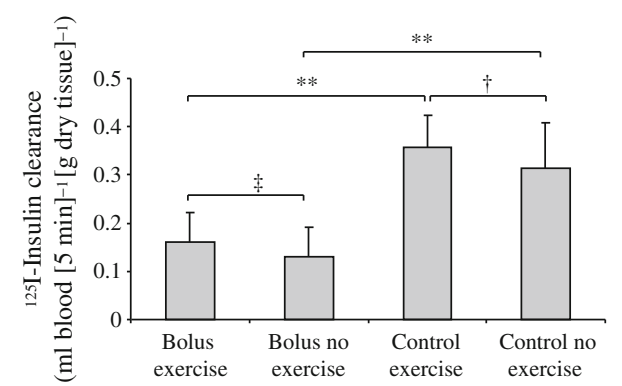

Fig. 5 Insulin clearance in insulin bolus vs control animals separated by limbs exposed to exercise vs those that were not exercised. Differences between insulin bolus and controls (bolus exercise vs control exercise $p=0.0013$, bolus no exercise vs control no exercise $p=0.0067$ ) were significant, as were differences between the insulin bolus exercised vs non-exercised limbs $(p=0.023)$. There was no significant difference between the control exercised and nonexercised limbs $(p=0.44) .{ }^{*} p<0.01,{ }^{\dagger} p=0.076,{ }^{*} p<0.03$. Error bars represent $\mathrm{SD}$ a
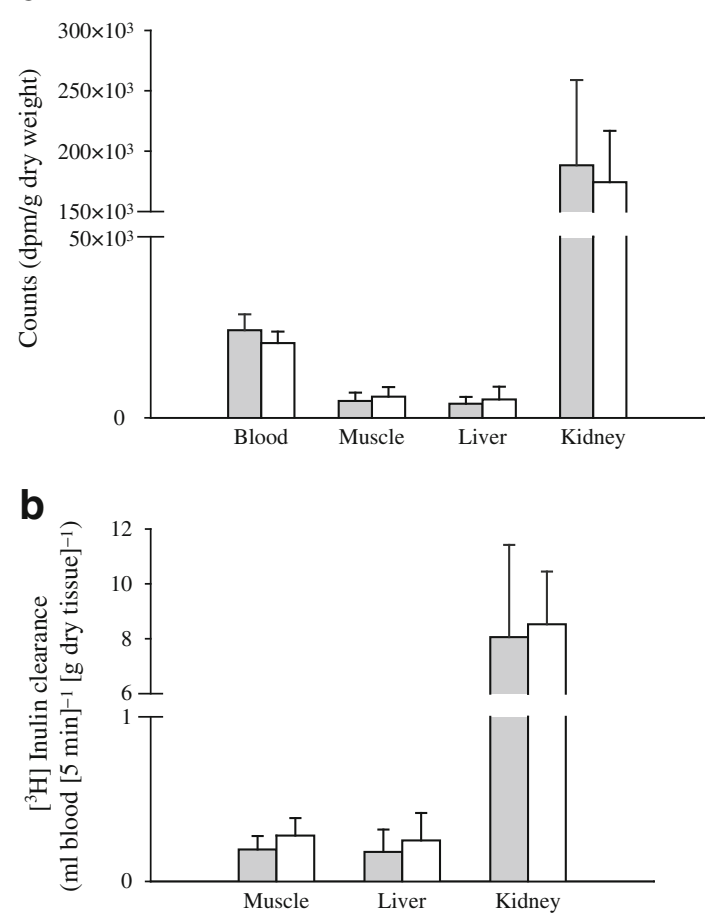

Fig. 6 a $\left[{ }^{3} \mathrm{H}\right]$ Inulin uptake in blood, skeletal muscle, liver and kidney at 5 min after tracer injection accompanied by either unlabelled inulin (grey bars) or saline (white bars) $(n=6-8$ each). Amounts are in counts $(\mathrm{dpm})$ per gram dry tissue. $\mathbf{b}\left[{ }^{3} \mathrm{H}\right]$ Inulin clearance in skeletal muscle, liver and kidney. There was no significant effect of unlabelled inulin (grey bars) in any tissue surveyed. Error bars represent SD

$\left[{ }^{3} \mathrm{H}\right]$ Inulin disappearance from the blood and uptake by skeletal muscle, liver and kidney was not significantly affected by the presence of unlabelled inulin (Fig. 6a). $\left[{ }^{3} \mathrm{H}\right]$ inulin clearance in skeletal muscle, liver and kidney was also not significantly affected by the presence of unlabelled inulin (Fig. 6b), consistent with its uptake and clearance occurring via a non-receptor-mediated pathway.

\section{Discussion}

This study was prompted by the continued uncertainty as to whether insulin accesses skeletal muscle by a receptor-mediated transport process or by a diffusionlimited process. Here we used a very brief exposure to ${ }^{125}$ I-labelled insulin $(5 \mathrm{~min})$ to address the initial disappearance of ${ }^{125}$ I-labelled insulin from plasma, which involves its handling by the vascular endothelium. Previous work has nicely demonstrated that insulin's accessing, binding to and activating the insulin receptor in skeletal muscle requires $20 \mathrm{~min}$ or more [1-3]. Accordingly, the myocyte receptor pool would not be saturated during the short $(5 \mathrm{~min})$ radioisotope exposure used here. Another design advantage is that, during the 
first 5 min after injection of ${ }^{125}$ I-labelled insulin, 85\% of the TCA-precipitable iodine remains associated with an insulin molecule that is immune and receptor reactive [11]. Thus the current results should reflect predominantly intact ${ }^{125}$ I-labelled insulin interacting with receptors on the vessel wall within muscle. Based on these considerations, the ability of unlabelled insulin to decrease the clearance of labelled insulin strongly supports the hypothesis that a significant fraction of insulin's movement from the vascular compartment into muscle involves a receptor-mediated, saturable process.

An early study by Rasio [15], and several subsequent studies $[10,11]$ demonstrated the interesting phenomenon that, when observing the disappearance of intravenously injected iodine-labelled insulin, the subsequent injection of a large unlabelled insulin bolus not only slows the disappearance of label (as was seen here) but transiently increases the plasma concentration of iodinated insulin. This does not occur with labelled inulin or albumin [10]. It has been suggested that this is due to the release of reversibly-bound iodinated insulin from insulin receptors on the endothelial cell. The several previous studies of radioiodinated hindlimb insulin clearance $[10,11,15]$ relied on arterial-venous differences, and direct muscle sampling was not undertaken. Interestingly, labelled inulin is reported to enter muscle more rapidly than insulin [10]. As inulin has a molecular mass that approximates that of insulin, this suggests that size alone does not determine tissue penetration. However, the concern was raised that the labelled insulin used in these early studies may behave differently from native insulin [8]. In the current study, the labelled insulin used is known to mimic the receptor binding properties of native insulin [16] and our data also support the hypothesis that insulin's trans-endothelial transport is via a saturable process. As with previous studies, we also found that $\left[{ }^{3} \mathrm{H}\right]$ inulin transport was not affected by the presence of unlabelled inulin. This further suggests that insulin's trans-endothelial transport is not dependent only on size and is more likely to involve a specific transport mechanism.

Subsequent work in cultured endothelial cells has suggested that the trans-endothelial transport of insulin involves its associating with the insulin receptor [17]. We confirmed this and also observed that the IGF-1 receptor could likewise facilitate insulin's movement across cultured endothelial cells [9]. This may be of particular importance when plasma insulin concentrations are pharmacologically elevated as the IGF-1 receptors on endothelial cells are much more abundant than insulin receptors [18].

The findings reported here, together with other recent findings [9], may allow some reconciliation of the seemingly conflicting reports as to whether muscle insulin uptake is a mediated process. The doses of unlabelled insulin would be sufficient to compete with insulin binding to either the insulin or the IGF-1 receptor. For example, Steil et al. measured insulin concentrations in lymph draining dog hindlimb muscle as a surrogate for interstitial fluid [8]. They found that, paradoxically, the ratio of plasma insulin concentration to lymph insulin concentration decreased when the plasma concentration was raised from $\sim 300$ to $\sim 30,000 \mathrm{pmol} / \mathrm{l}$. Such a finding cannot be explained by a simple diffusional process, which would predict a constant ratio between plasma and lymph. The authors suggest that this enhanced insulin delivery could be due to an expanded capillary surface that results from insulin recruiting skeletal muscle microvasculature. However, this seems unlikely as muscle microvascular recruitment by insulin appears essentially maximal at insulin concentrations of $300 \mathrm{pmol} / 1$ [19]. An alternative, and seemingly quite plausible, explanation involves insulin being transported by the IGF-1 receptor at the pharmacological insulin concentrations tested in that study. The ability of the endothelial cell IGF-1 receptor to be activated by insulin concentrations above $1,000 \mathrm{pmol} / 1$ [20] and to transport insulin across endothelial cells has been demonstrated [9]. The much greater abundance of IGF-1 receptors relative to insulin receptors in the endothelium $[18,20]$ would further facilitate this transport pathway.

It should be noted that, while our data indicate a saturable component to insulin uptake by skeletal muscle vasculature, they do not eliminate the possibility of a contribution by a non-saturable process to overall transendothelial insulin transport. Such a non-saturable process could be either para-cellular or trans-cellular. The latter could involve simple pinocytosis by a vesicular transport process, as has been described for albumin [21]. It is also possible that at different levels of the muscle microvasculature the relative contributions from a saturable vs a nonsaturable process may differ. In this regard, venous endothelium is thought to be significantly more permeable than capillary endothelium in some tissues [22].

In summary, the current study indicates that transendothelial transport of insulin in vivo involves a saturable process consistent with an important role for the endothelial cell insulin receptor. The rate-limiting nature of insulin's trans-endothelial transport for its metabolic actions in muscle underscores the importance of defining the cellular and molecular processes involved.

Acknowledgements This work was supported by NIH grants DK57878, DK073759 and ADA 1-11 BS-06 (E.J. Barrett) and a postdoctoral training fellowship from NIH T32-DK 007320-30 to S. Majumdar.

Contribution statement $\mathrm{SM}, \mathrm{AJG}, \mathrm{ACI}$ and VF contributed to the design, conduct, data analysis and manuscript preparation. EJB contributed to the planning, design, data analysis, manuscript preparation and support for the study. All authors approved the final manuscript. 
Duality of interest The authors declare that there is no duality of interest associated with this manuscript.

\section{References}

1. Freidenberg GR, Suter SL, Henry RR, Reichart D, Olefsky JM (1991) In vivo stimulation of the insulin receptor kinase in human skeletal muscle. Correlation with insulin-stimulated glucose disposal during euglycemic clamp studies. J Clin Investig 87:2222-2229

2. Miles PD, Levisetti M, Reichart D, Khoursheed M, Moossa AR, Olefsky JM (1995) Kinetics of insulin action in vivo. Identification of rate-limiting steps. Diabetes 44:947-953

3. Freidenberg GR, Suter S, Henry RR, Nolan J, Reichart D, Olefsky JM (1994) Delayed onset of insulin activation of the insulin receptor kinase in vivo in human skeletal muscle. Diabetes 43:118-126

4. Yang YJ, Hope ID, Ader M, Bergman RN (1994) Importance of transcapillary insulin transport to dynamics of insulin action after intravenous glucose. Am J Physiol 266:E17-25, Erratum in Am J Physiol 1997;173(2 Pt 1): section E

5. Yang YJ, Hope ID, Ader M, Bergman RN (1989) Insulin transport across capillaries is rate limiting for insulin action in dogs. J Clin Invest 84:1620-1628

6. Yang YJ, Hope I, Ader M, Poulin RA, Bergman RN (1992) Doseresponse relationship between lymph insulin and glucose uptake reveals enhanced insulin sensitivity of peripheral tissues. Diabetes 41:241-253

7. Chiu JD, Richey JM, Harrison LN et al (2008) Direct administration of insulin into skeletal muscle reveals that the transport of insulin across the capillary endothelium limits the time course of insulin to activate glucose disposal. Diabetes 57:828-835

8. Steil GM, Ader M, Moore DM, Rebrin K, Bergman RN (1996) Transendothelial insulin transport is not saturable in vivo. No evidence for a receptor-mediated process. J Clin Invest 97:1497-1503

9. Wang H, Liu Z, Li G, Barrett EJ (2006) The vascular endothelial cell mediates insulin transport into skeletal muscle. Am J Physiol Endocrinol Metab 291:E323-332
10. Sonksen PH, McCormick JR, Egdahl RH, Soeldner JS (1971) Distribution and binding of insulin in the dog hindlimb. Am J Physiol 221:1672-1680

11. Zeleznik AJ, Roth J (1978) Demonstration of the insulin receptor in vivo in rabbits and its possible role as a reservoir for the plasma hormone. J Clin Invest 61:1363-1374

12. Sherwin RS, Kramer KJ, Tobin JD et al (1974) A model of the kinetics of insulin in man. J Clin Invest 53:1481-1492

13. Eggleston EM, Jahn LA, Barrett EJ (2007) Hyperinsulinemia rapidly increases human muscle microvascular perfusion but fails to increase muscle insulin clearance: evidence that a saturable process mediates muscle insulin uptake. Diabetes $56: 2958-2963$

14. Inyard AC, Clerk LH, Vincent MA, Barrett EJ (2007) Contraction stimulates nitric oxide independent microvascular recruitment and increases muscle insulin uptake. Diabetes 56:2194-2000

15. Rasio EA (1969) The displacement of insulin from blood capillaries. Diabetologia 5:416-419

16. Gliemann J, Sonne O, Linde S, Hansen B (1979) Biological potency and binding affinity of monoiodoinsulin with iodine in tyrosine A14 or tyrosine A19. Biochem Biophys Res Commun 87:1183

17. King GL, Johnson SM (1985) Receptor-mediated transport of insulin across endothelial cells. Science 227:1583-1586

18. Chisalita SI, Arnqvist HJ (2004) Insulin-like growth factor I receptors are more abundant than insulin receptors in human micro- and macrovascular endothelial cells. Am J Physiol Endocrinol Metab 286:E896-901

19. Zhang L, Vincent MA, Richards SM et al (2004) Insulin sensitivity of muscle capillary recruitment in vivo. Diabetes 53:447-453

20. Li G, Barrett EJ, Wang H, Chai W, Liu Z (2005) Insulin at physiological concentrations selectively activates insulin but not insulin-like growth factor I (IGF-I) or insulin/IGF-I hybrid receptors in endothelial cells. Endocrinology 146:4690-4696

21. John TA, Vogel SM, Tiruppathi C, Malik AB, Minshall RD (2003) Quantitative analysis of albumin uptake and transport in the rat microvessel endothelial monolayer. Am J Physiol Lung Cell Mol Physiol 284:L187-196

22. Aird WC (2007) Phenotypic heterogeneity of the endothelium: II. Representative vascular beds. Circ Res 100:174-190 